\title{
COVID-19: Effects of environmental conditions on the propagation of respiratory droplets
}

\author{
Lei Zhao ${ }^{1}$, Yuhang Qi ${ }^{1}$, Paolo Luzzatto-Fegiz ${ }^{1}$, Yi Cui ${ }^{2,3}$, Yangying Zhu ${ }^{1 *}$ \\ ${ }^{1}$ Department of Mechanical Engineering, University of California Santa Barbara, Santa Barbara \\ CA, USA \\ ${ }^{2}$ Department of Materials Science and Engineering, Stanford University, Stanford, CA, USA \\ ${ }^{3}$ Stanford Institute for Materials and Energy Sciences, SLAC National Accelerator Laboratory, \\ Menlo Park, CA, USA
}

*To whom correspondence should be addressed Yangying Zhu, Email: yangying@ucsb.edu 


\section{Model Formulations ${ }^{1-3}$}

To model the propagation of a respiratory droplets, we inherited model frameworks developed by Wells, ${ }^{1}$ Xie et $a l^{2}$ and Kukkonen et al. ${ }^{3}$ For convenience to the readers, we briefly provide key equations here. When a droplet with an initial diameter of $\mathrm{d}_{0}$ and temperature $\mathrm{T}_{0}$ is moving in moist air with temperature $\mathrm{T}_{\infty}$ and relative humidity $\mathrm{RH}$, the evaporative flux of the droplet is determined by the difference of vapor pressure near the droplet surface $p_{\mathrm{vs}}$ and that of the ambient environment $\mathrm{p}_{\mathrm{v} .}{ }^{2,3}$

$\frac{d m_{p}}{d t}=\frac{2 \pi d p M_{v} D_{\infty}}{R T_{\infty}} \cdot C \cdot S h \cdot \ln \left(\frac{p-p_{v s}}{p-p_{v \infty}}\right)$

where $m_{p}$ is the mass of the droplet, $\mathrm{t}$ is the time, $\mathrm{d}$ is the time-dependent diameter of the droplet, $M_{v}$ is the molecular mass of the droplet, $D_{\infty}$ is the binary diffusion coefficient of vapor in the air, $R$ is the universal gas constant and $\mathrm{p}$ is the total pressure of the air. $C$ is the correction factor due to temperature dependence of diffusion coefficient. ${ }^{4}$

$$
C=\frac{T_{\infty}-T}{T_{\infty}^{\lambda-1}} \frac{2-\lambda}{T_{\infty}^{2-\lambda}-T^{2-\lambda}}
$$

where $\mathrm{T}$ is the temperature of the droplet and $\lambda$ is a constant specifically for water. $S h$ is the Sherwood number.

$S h=1+0.3 R e^{\frac{1}{2}} S c^{\frac{1}{3}}$

Re and Sc are the Reynolds number and Schmidt number, which can be calculated as:

$\operatorname{Re}=\frac{\rho_{a}\left(V-V_{a i r}\right) d}{\mu}, S c=\frac{\mu}{\rho_{a} D_{\infty}}$

where $\rho_{\mathrm{a}}$ is the density of the air, $\mathrm{V}_{\text {air }}$ is the wind speed, $\mathrm{V}$ is the droplet velocity and $\mu$ is the dynamic viscosity of the air.

$\mathrm{p}_{\mathrm{vs}}$ is the vapor pressure at the droplet surface and is lowered by the dissolved substances in its solution, which can be described by the Raoult's law $p_{v s}=f_{w} p_{v 0}(T)$, where $\mathrm{f}_{\mathrm{w}}$ is the mole fraction of water in the solution and $p_{\mathrm{v} 0}$ is the saturation vapor pressure at temperature $\mathrm{T}$. The composition of a respiratory droplet can be extremely complex and may contain pathogens, proteins, salt, and surfactants. ${ }^{2}$ In this study, we assume the respiratory droplet as a physiological saline solution with $0.9 \%$ weight fraction of sodium chloride. During the evaporation process, 
sodium chloride begins to precipitate once the saturating concentration has been reached. The asformed $\mathrm{NaCl}$ crystal will serve as a nest where SARS-CoV-2 can reside. Its diameter $\mathrm{d}_{\mathrm{r}}$ after dryout can be calculated as:

$d_{r}=\left(\frac{6 m_{s}}{\pi \rho_{s}}\right)^{\frac{1}{3}}$

where $\mathrm{m}_{\mathrm{s}}$ is the mass of $\mathrm{NaCl}$ initially dissolved in the droplet and $\rho_{\mathrm{s}}$ is the density of $\mathrm{NaCl}$ crystal. In a recent study, ${ }^{5}$ the average viral load in human respiratory liquids is measured to be $7 \times 10^{6}$ copies per milliliter. For a respiratory droplet with initial diameter of $100 \mu \mathrm{m}$, the average number of viruses contained in the droplet is only 3.66. Considering SARS-CoV-2 is mostly $100 \mathrm{~nm}$ in diameter, ${ }^{6}$ the effect of viruses contained in the droplet on the terminal size of aerosol particles $\left(d_{r} \approx 15 \mu \mathrm{m}\right)$ is negligible.

The heat transfer between the droplet and the air is dominated by evaporation, convection, and radiation. An energy balance equation can be derived as: $:^{1,2}$

$m_{p} c_{p} \frac{d T}{d t}=2 \pi d k_{a}\left(T_{\infty}-T\right) \cdot N u+L_{v} \frac{d m_{p}}{d t}+\pi d^{2} \Gamma\left(T_{\infty}^{4}-T^{4}\right)$

where $c_{p}$ is the specific heat capacity of the droplet, $k_{a}$ is the thermal conductivity of the air, $L_{v}$ is the latent heat of vaporization and $\Gamma$ is the Stefan-Boltzmann constant. $\mathrm{Nu}$ is the Nusselt number. $N u=1+0.3 \operatorname{Re}^{\frac{1}{2}} \operatorname{Pr}^{\frac{1}{3}}$

$\operatorname{Pr}=\frac{c_{a} \mu}{k_{a}}$ is the Prandtl number, where $c_{a}$ is the specific heat capacity of the air.

The displacement of velocity of the droplet can be calculated by considering gravity, buoyancy and air drag as the dominating factors. ${ }^{1,2}$

$m_{p} \frac{d \vec{V}}{d t}=m_{p} \vec{g}\left(1-\frac{\rho_{a}}{\rho}\right)-\frac{1}{2} \frac{\pi d^{2}}{4} C_{d} \rho_{a}\left|\vec{V}-\vec{V}_{a i r}\right|\left(\vec{V}-\vec{V}_{a i r}\right)+F_{B}$

where $\vec{g}$ is the gravity and $\rho$ is the density of the droplet. $\mathrm{C}_{\mathrm{d}}$ is the drag coefficient, which can be determined by the following equation.

$C_{d}= \begin{cases}0.424 & R e>1000 \\ \frac{24}{R e}\left(1+\frac{1}{6} R e^{\left(\frac{2}{3}\right)}\right) & R e \leq 1000\end{cases}$

$F_{B}$ is the random Brownian force, which will be discussed in the next section. 


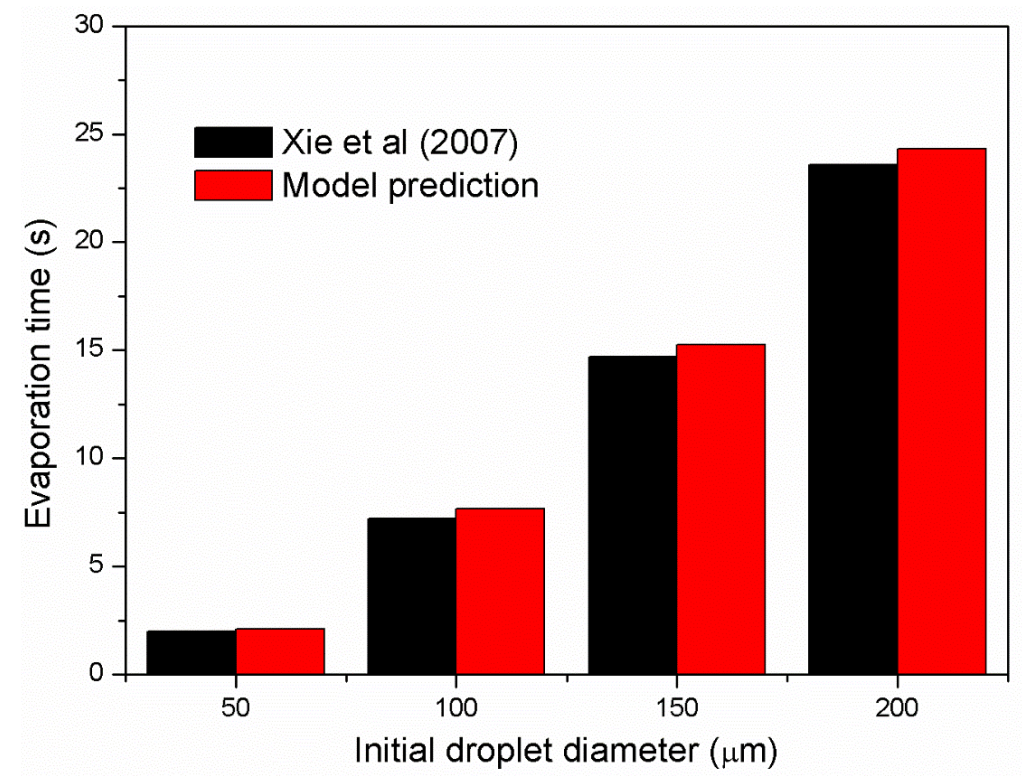

Figure S1. Comparison of the calculation results to Xie et al. (2007). ${ }^{2}$ The figure describes the evaporation time of a falling droplet $\left(\mathrm{T}_{0}=33^{\circ} \mathrm{C}\right)$ in $\operatorname{dry}$ air $\left(\mathrm{T}_{\infty}=25^{\circ} \mathrm{C}, \mathrm{RH}=0\right)$.

All simulations of droplets were stopped if 1) the droplet has completely dehydrated, i.e., $\mathrm{d} \leq \mathrm{d}_{\mathrm{r}}$, where $\mathrm{d}_{\mathrm{r}}$ is the diameter of droplet nuclei formed by residues; or 2 ) the droplet has descended to the level of another person's hands, i.e., $\left|\mathrm{L}_{\mathrm{z}}\right| \geq \mathrm{H} / 2$, where $\mathrm{L}_{\mathrm{z}}$ is the vertical displacement. Moist air is used to calculate the dependence of gas properties on RH. Those temperature dependent parameters are taken from Xie et $a l^{2}$ and Kukkonen et al. (1989). ${ }^{3}$ ) We have compared our results to Xie $e t a l^{2}$, as shown in Figure S1. The slight difference may be attributed to the small differences in the thermophysical properties of water and moist air that were adopted. In particular, we use a specific heat capacity of $4.2 \mathrm{~kJ} /(\mathrm{kg} \mathrm{K})$ for water.

\section{Effect of Brownian Motion}

Most respiratory droplets are smaller than $100 \mu \mathrm{m}$. Once they dry out, the droplet nuclei left behind are usually smaller than $10 \mu \mathrm{m}$. Therefore, the movement of such particles becomes sensitive to impacts from fast moving air molecules, which poses a random component $F_{B}$ in the kinematic equation, as presented in equation S8. F $\mathrm{B}$ is supposed to vary extremely rapidly over the 
time of any observation. The effect of the fluctuating force can be summarized by giving its first and second moments: ${ }^{7}$

$$
\left\langle F_{B}(t)\right\rangle=0,\left\langle F_{B}\left(t_{1}\right) F_{B}\left(t_{2}\right)\right\rangle=2 \beta k_{B} T \delta\left(t_{1}-t_{2}\right)
$$

The average $\langle\ldots\rangle_{\text {is }}$ an average with respect to the distribution of the realizations of the stochastic variable $\mathrm{F}_{\mathrm{B}}(\mathrm{t})$. The delta function $\delta\left(t_{1}-t_{2}\right)$ in time indicates that there is no correlation between impacts in any distinct time intervals $t_{1}$ and $t_{2} . \beta$ is the damping coefficient and can be derived from the Einstein relation.

$\beta=3 \pi \mu d$

The fluctuating force $\mathrm{F}_{\mathrm{B}}$ has a Gaussian distribution with the moments specified in equation S10. Therefore, the effect of Brownian force $F_{B}$ can be estimated by comparing it to the gravity.

$$
\frac{F_{B}}{m_{p} g}=\frac{\sqrt{2 \beta k_{B} T}}{\frac{1}{6} \pi d^{3} \rho}
$$

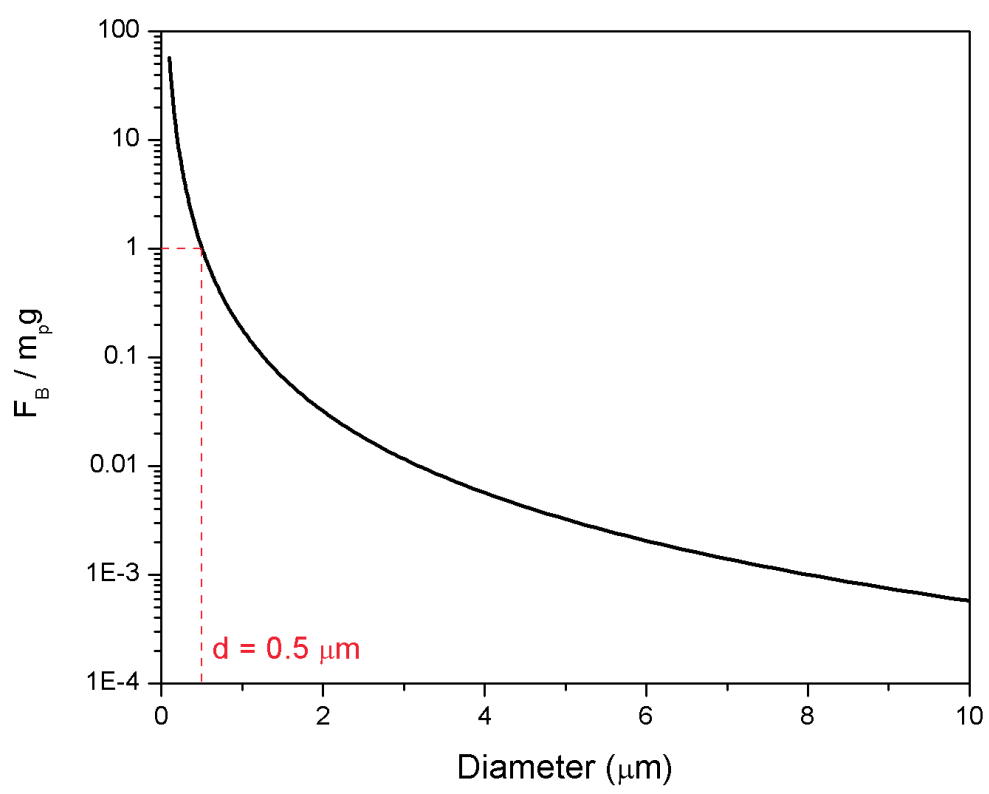

Figure S2. Effect of Brownian force at different length scales

Figure $\mathrm{S} 2$ presents the comparison of $\mathrm{F}_{\mathrm{B}}$ to gravity at different nuclei diameters. It is found that the Brownian force $F_{B}$ is comparable to gravity only if the nuclei size becomes smaller than $0.5 \mu \mathrm{m}$. In this case, the corresponding initial diameter of the droplet calculated from equation S5 must be smaller than $3.4 \mu \mathrm{m}$. However, respiratory droplets are larger than $5 \mu \mathrm{m}$ according to previous measurements. ${ }^{8}$ 
The accumulative effect of Brownian force on the movement of droplet nuclei can be accounted for in an alternative way. Assuming that the droplet nuclei are at equilibrium in that gravity equals to the air drag, then the motion of those nuclei become purely diffusive and the dependent displacement can be described as:

$\Delta x(t)=\int_{0}^{t} V^{*}\left(t^{\prime}\right) \mathrm{d} t^{\prime}$

where $\mathrm{V}^{*}$ is the fluctuating velocity resulting from the random Brownian force. The time-averaged displacement $\overline{\Delta x}$ is equal to 0 , but the mean square displacement $\left\langle\Delta x(t)^{2}\right\rangle$ can be evaluated as: $\left\langle\Delta x(t)^{2}\right\rangle=2 D t=\frac{2 k_{B} T}{3 \pi \mu d} t$

Therefore, the average deviation of droplet nuclei in a duration of $\mathrm{t}$ is:

$\langle|\Delta x(t)|\rangle=\sqrt{\frac{2 k_{B} T}{3 \pi \mu d_{r}} t}$

where $d_{r}$ is the diameter of the droplet nucleus. For $T=300 \mathrm{~K}$ and $d_{r}=1 \mu \mathrm{m} \mathrm{um}$, we find that its expected moving distance is only $0.03 \mathrm{~m}$ in 5000 seconds, which is negligible in the transmission of both aerosol particles and droplets.

To conclude, we find that the effect of Brownian motion on the transmission of respiratory droplets and droplet nuclei is negligible, in that 1) the fluctuating Brownian force is trivial compared to the gravity for the size of interest $(\mathrm{d}>1 \mu \mathrm{m}) ; 2)$ the deviation of those particles from their original induced by Brownian motion is negligible.

\section{Size and Distribution of Speech Droplets}

The size and distribution of speech droplets, i.e., respiratory droplets expelled by speaking, are taken from a work published by J. P, Duguid. ${ }^{8}$ Here we present a probability density distribution of different initial diameters of speech droplets in Figure S3. 


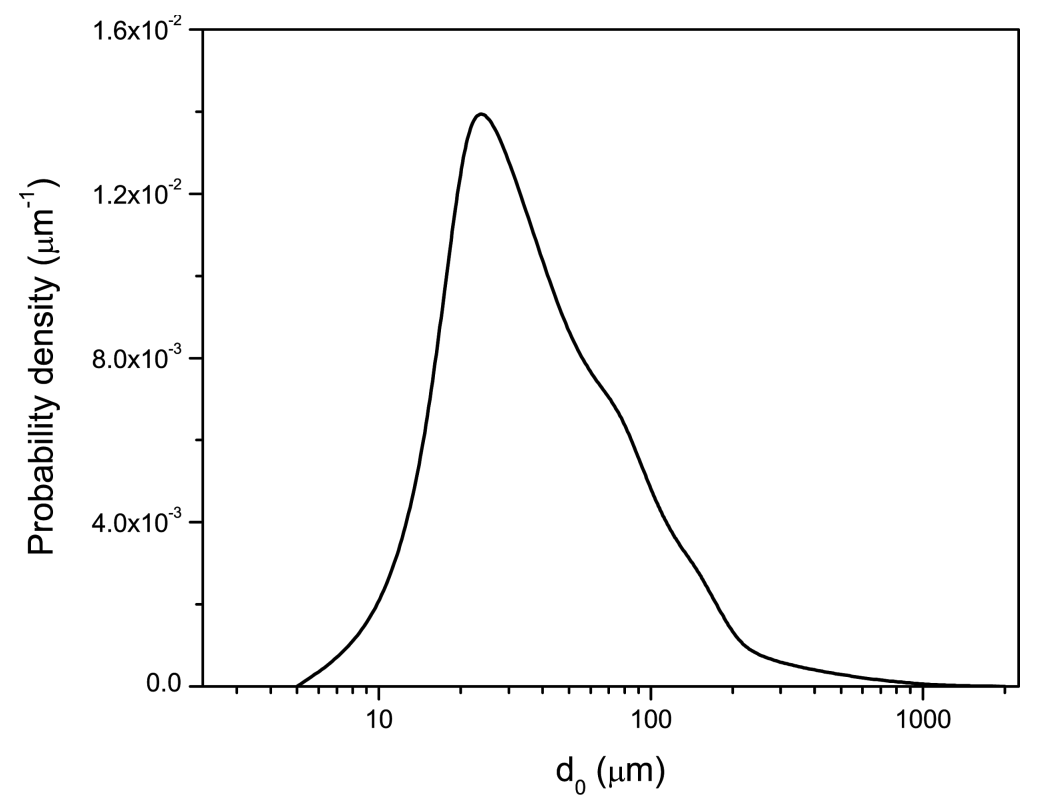

Figure S3. Probability density distribution of the initial diameter of speech droplets ${ }^{8}$

\section{Kinematic Analysis of Aerosol Particle Transport}

Once the droplet has dried out, as-formed aerosol particles will suspend in air for a long time and eventually fall on the ground due to gravity. In this study, we assume a laminar and horizontal airflow directed from a patient to another individual to mimic the worst scenario. Therefore, the vertical movement of aerosol particles is solely controlled by gravity, buoyancy and air drag. Because the downward velocity $\mathrm{v}_{\mathrm{z}}$ of droplet nuclei are usually on the order of $10^{-5}-10^{-4}$ $\mathrm{m} / \mathrm{s}, \operatorname{Re}<<1$ and therefore we can assume a Stokes flow around the droplet nuclei.

$m_{r} \frac{d v_{z}}{d t}=m_{r} g\left(1-\frac{\rho_{a}}{\rho}\right)-6 \pi \mu r v_{z}$

where $\mathrm{m}_{\mathrm{r}}$ is the mass and $\mathrm{r}$ is the radius of the droplet nucleus. Equation S16 can be solved with initial condition of $\mathrm{v}_{\mathrm{z}}=\mathrm{v}_{0}$ at $\mathrm{t}=0$, where $\mathrm{v}_{\mathrm{t}}$ is the terminal velocity of the droplet.

$v_{z}=\left(v_{t}-v_{e}\right) e^{-\frac{t}{\tau}}+v_{e}$

$\tau$ is the time constant.

$\tau=\frac{m_{r}}{6 \pi \mu R}=\frac{2 \rho r^{2}}{9 \mu}$

$\mathrm{V}_{\mathrm{e}}=\mathrm{g} \tau\left(1-\rho_{\mathrm{a}} / \rho\right)$ is the falling velocity of the aerosol particle by assuming gravity is entirely balanced by buoyancy and air drag. 


\section{Evaporation Dynamics of Droplets}

Previous study has shown that the temperature of a droplet can reach the wet bulb quickly, usually within 1 second, ${ }^{2}$ owing to the large latent heat required to evaporate. Therefore, the effect of heat transfer is not significant on the evaporation dynamics, as the droplet stays at $\mathrm{T}_{\mathrm{wb}}$ throughout the evaporation process. We further examine the evaporation dynamics of a speech droplet $\left(\mathrm{d}_{0}=100 \mu \mathrm{m}, \mathrm{T}_{0}=33{ }^{\circ} \mathrm{C}, \mathrm{v}_{0}=4.1 \mathrm{~m} / \mathrm{s}\right)$ in different environmental conditions. The timedependent characteristics of an evaporating speech droplet is shown in Figure S4. In Figure S4, the droplet completely dries out after its diameter reaches the corresponding residue diameter. In Figure S4(a), the evaporation time for a $100 \mu \mathrm{m}$ droplet can be decreased from 17 seconds to 9 seconds when the temperature is increased from $10{ }^{\circ} \mathrm{C}$ to $30{ }^{\circ} \mathrm{C}$. Figure $\mathrm{S} 4(\mathrm{~b})$ presents that the droplet evaporation can be expedited by 2 times when the relative humidity is decreased from 0.8 to 0.4 . Both the temperature and relative humidity impacts the droplet evaporation dynamics by changing the saturated vapor pressure.
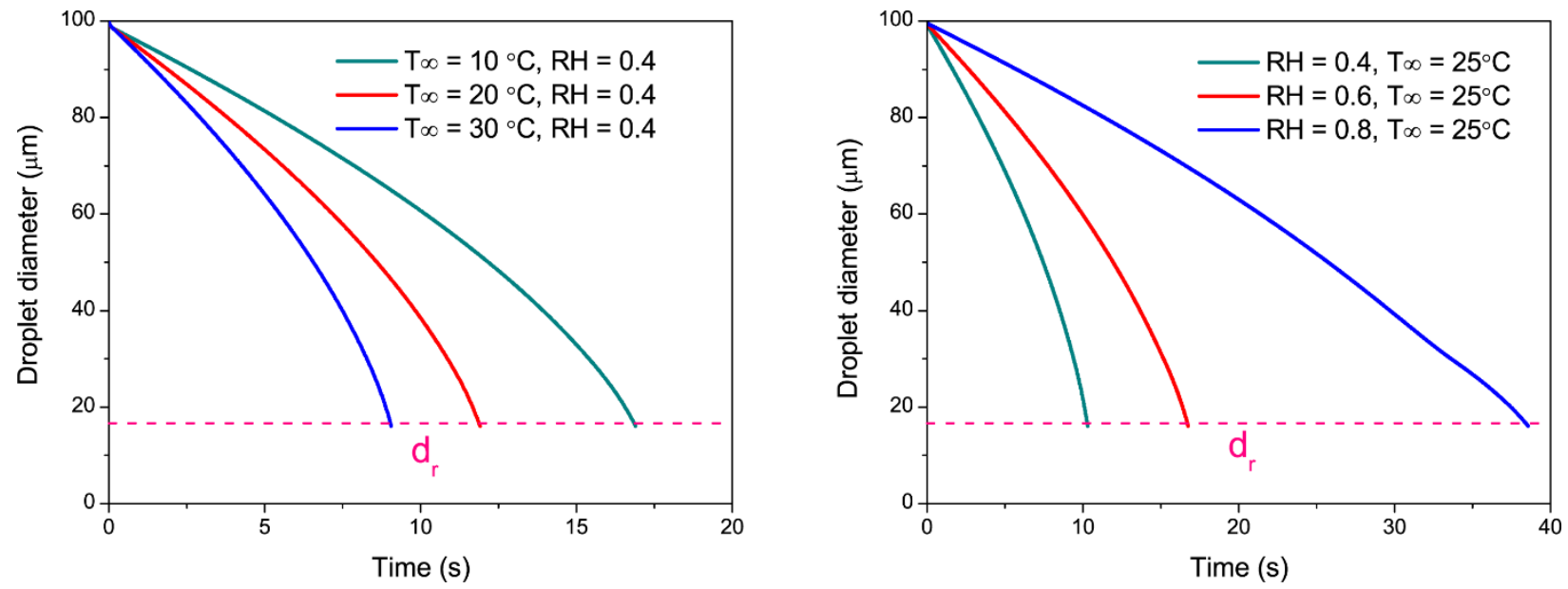

Figure S4. Diameter change of a speech droplet $\left(\mathrm{T}_{0}=33^{\circ} \mathrm{C}, \mathrm{v}_{0}=4.1 \mathrm{~m} / \mathrm{s}\right)$ with initial diameter $\mathrm{d}_{0}$ of $=100 \mu \mathrm{m}$ under (a) relative humidity of 0.4 and (b) temperature of $25^{\circ} \mathrm{C}$. The background air velocity is $0.3 \mathrm{~m} / \mathrm{s}$.

\section{Dynamic Behaviors of Droplets with Different $d_{0}$}

We analyze the behaviors of respiratory droplets $\left(\mathrm{T}_{0}=33^{\circ} \mathrm{C}\right)$ with different initial diameter $\mathrm{d}_{0}$ produced by speaking $\left(\mathrm{v}_{0}=4.1 \mathrm{~m} / \mathrm{s}\right)$ in typical indoor air $\left(\mathrm{T}_{\infty}=23{ }^{\circ} \mathrm{C}\right.$ and $\mathrm{RH}=0.5$ and $\mathrm{V}_{\text {air }}=$ 
$0.3 \mathrm{~m} / \mathrm{s}$ ). The trajectory of a droplet is analyzed in terms of the vertical distance $\mathrm{L}_{z}$ and horizontal distance $L_{x}$. Figure S5(a) shows that droplets with diameter smaller than $73.5 \mu \mathrm{m}$ can completely dehydrate into aerosol particles and therefore only descend a vertical distance less than $\mathrm{H} / 2$. Droplets larger than $73.5 \mu \mathrm{m}$ fall below the level of hands $(\mathrm{H} / 2)$. A critical droplet diameter $\mathrm{d}_{\mathrm{c}}$ can be defined by identifying the initial diameter below which droplets can fully evaporate before descending to the hands. Our results suggest that the maximum of $L_{x}$ occurs at $d_{0}=d_{c}$ as well (Figure $\mathrm{S} 5(\mathrm{~b})$ ). For $\mathrm{d}<\mathrm{d}_{\mathrm{c}}, \mathrm{L}_{\mathrm{x}}$ increases with respect to $\mathrm{d}_{0}$ because a larger droplet takes longer time to fully evaporate and thus travels further; as $d$ exceeds $d_{c}$, the droplet falls more quickly due to gravity resulting in a smaller $\mathrm{L}_{\mathrm{x}}$.
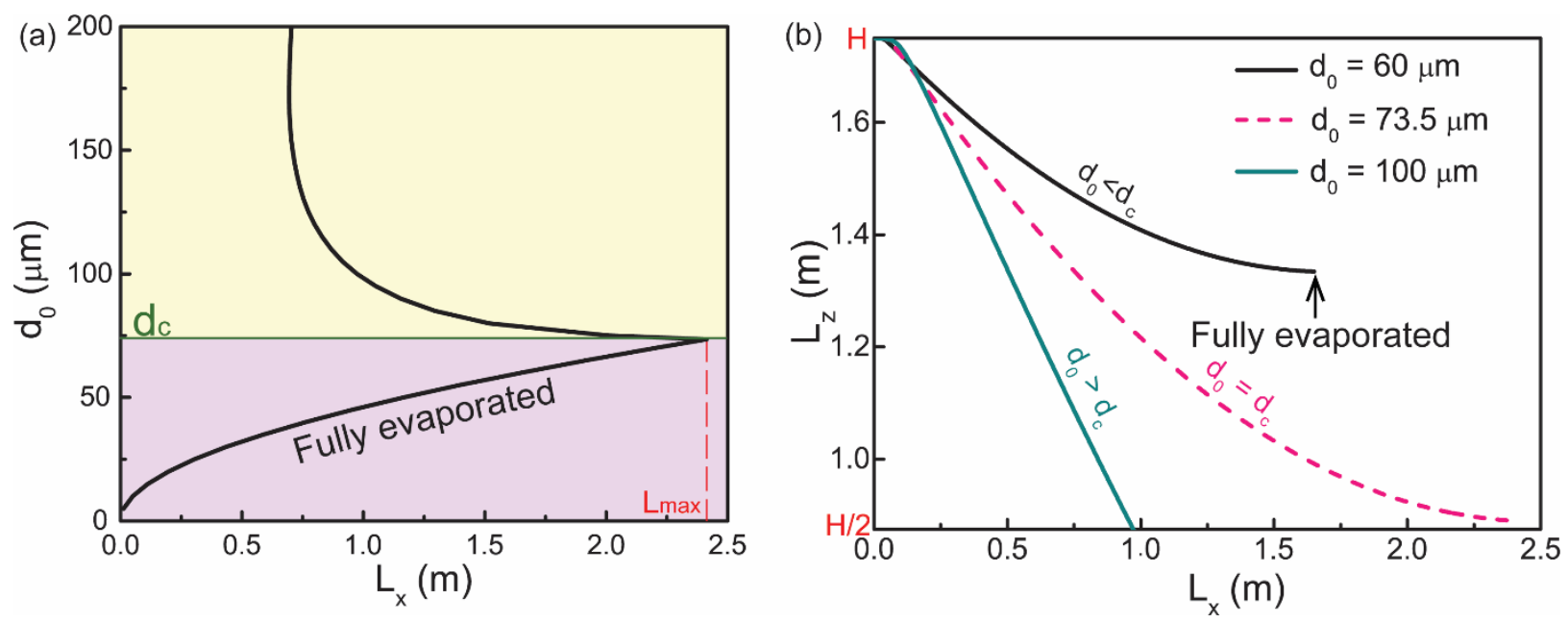

Figure S5. (a) The horizontal traveling distance of respiratory droplets before drying or descending to the level of hands. (b) Trajectories of droplets with different initial diameters. The droplet has an initial temperature of $\mathrm{T}_{0}=33{ }^{\circ} \mathrm{C}$ and air conditions are $\mathrm{T}_{\infty}=23{ }^{\circ} \mathrm{C}, \mathrm{RH}=0.5$ and $\mathrm{V}_{\text {air }}=0.3 \mathrm{~m} / \mathrm{s}$

\section{Viral Load in Respiratory Droplets}

If the concentration of SARS-CoV-2 is constant in all respiratory secretions, then the number of viruses $\mathrm{N}_{\mathrm{v}}$ in a respiratory droplet is determined by its size.

$N_{v}=\frac{\pi n d_{0}^{3}}{6}$ 
where $\mathrm{n}$ is the average number per unit volume. Based on the size distribution presented in Figure S3 and J. P, Duguid ${ }^{8}$, we calculated the percentage of viral load in each diameter range (Figure S6 (a)).

$\xi\left(d_{0}\right)=\frac{N_{v}\left(d_{0}\right)}{\sum_{d_{0}} N_{v}}$

We find that almost $96 \%$ of viruses produced by one expiration are carried in droplets with $\mathrm{d}_{0}>$ $200 \mu \mathrm{m}$. Therefore, the droplet contact transmission could be surprisingly dangerous.
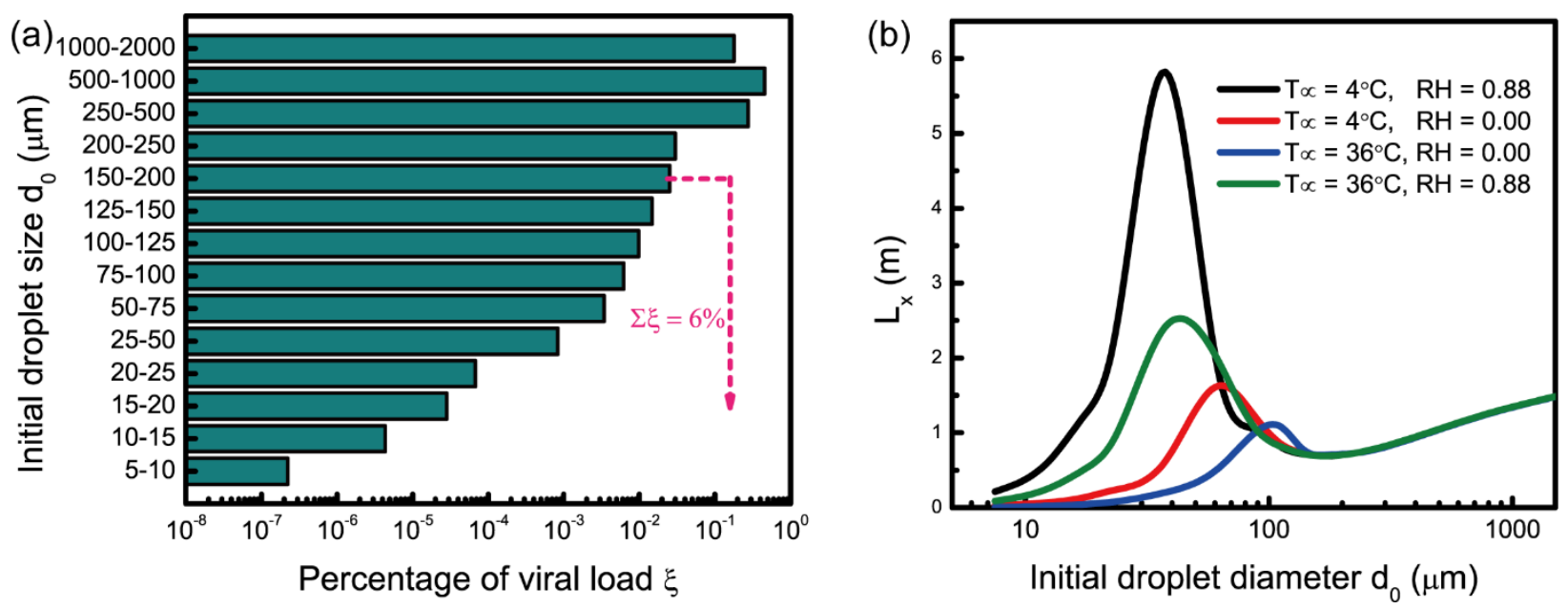

Figure S6. (a) Viral load distribution over different initial droplet size $d_{0}$. (b) Spreading distance $\mathrm{L}_{\mathrm{x}}$ for droplets with different initial diameter $\mathrm{d}_{0}$.

In order to obtain the distance-dependent viruses that one may receive, we also computed the traveling distance $\mathrm{L}_{\mathrm{x}}$ for different $\mathrm{d}_{0}$ and environmental conditions (Figure $\mathrm{S} 6$ (b)). By combining Figure S6 (a) and (b), we are able to plot the distance-dependent viral load in Figure S7, which characterizes the effectiveness of social distancing at different distances. 


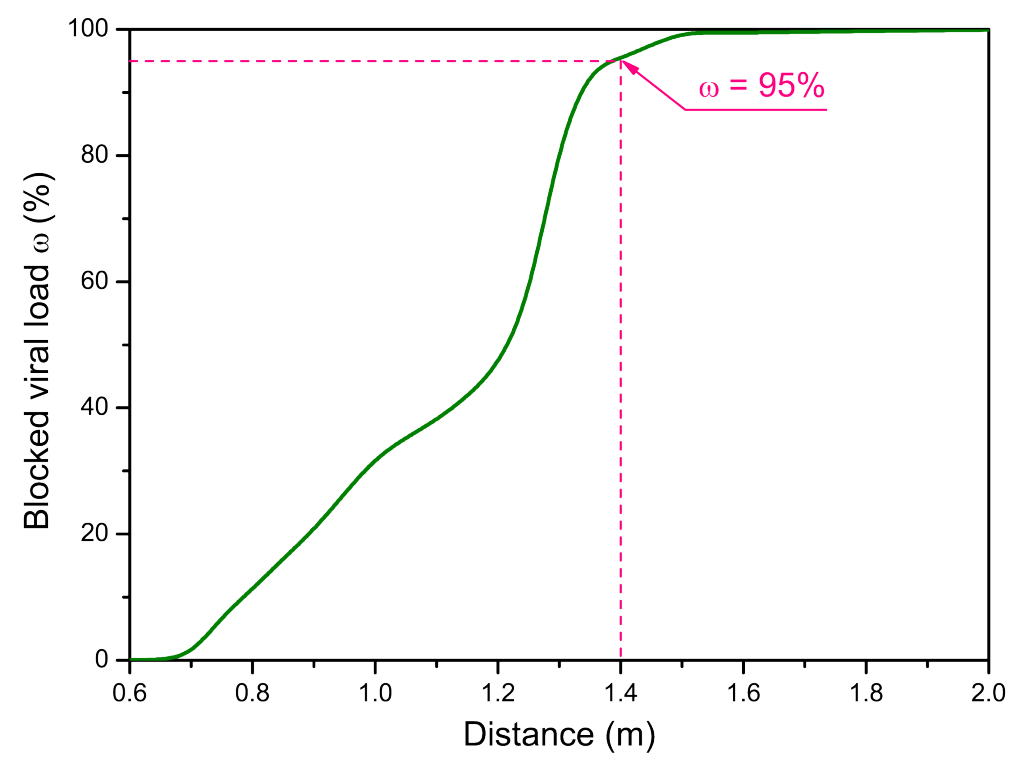

Figure S7. Effectiveness of practicing social distancing at different distance

Figure S6 (b) presents the traveling distance of different droplets at four extremes, i.e., cold and humid $\left(\mathrm{T}_{\infty}=4{ }^{\circ} \mathrm{C}, \mathrm{RH}=0.88\right)$, cold and dry $\left(\mathrm{T}_{\infty}=4{ }^{\circ} \mathrm{C}, \mathrm{RH}=0\right)$, hot and dry $\left(\mathrm{T}_{\infty}=36{ }^{\circ} \mathrm{C}, \mathrm{RH}\right.$ $=0)$, hot and humid $\left(\mathrm{T}_{\infty}=36^{\circ} \mathrm{C}, \mathrm{RH}=0.88\right)$. We find that the horizontal traveling of small droplets $\left(\mathrm{d}_{0}<100 \mu \mathrm{m}\right)$ is strongly dependent on environmental conditions; however, large droplets are inert and become insensitive to change of environmental conditions. Since most pathogens exist in large respiratory droplets, the curve of distance-dependent viral load in Figure S7 is not sensitive to environments. Therefore, we only demonstrate the viral load curve under typical condition $\left(\mathrm{T}_{\infty}=\right.$ $23{ }^{\circ} \mathrm{C}, \mathrm{RH}=0.50, \mathrm{~V}_{\text {air }}=0.3 \mathrm{~m} / \mathrm{s}$ ), and an environment-independent criterion can be used for relaxed social distancing.

\section{Suspension Time and Total Mass of Aerosol Particles}

By integrating equation (S17), the suspension time $t_{s}$ that is required for a particle to deposit on the ground can be calculated by solving the following equation:

$v_{e} t_{s}+\left(v_{t}-v_{e}\right) \tau\left(1-\exp \left(-\frac{t_{s}}{\tau}\right)\right)=\frac{L_{m}}{2}-L_{z}$ 
We then calculated the average suspension time $t_{m}$ of PM2.5 under different environmental conditions, as shown in Figure S8(a). Generally, PM2.5 can suspend in air for around 10 hours. We also find that the hot and dry temperature gives rise to a longer suspension time for PM2.5, as shown in Figure $S 8(b)$. The suspension time $t_{s}$ varies dramatically from 4 hours to around 10 hours when the diameter changes from $10 \mu \mathrm{m}$ to $1 \mu \mathrm{m}$.
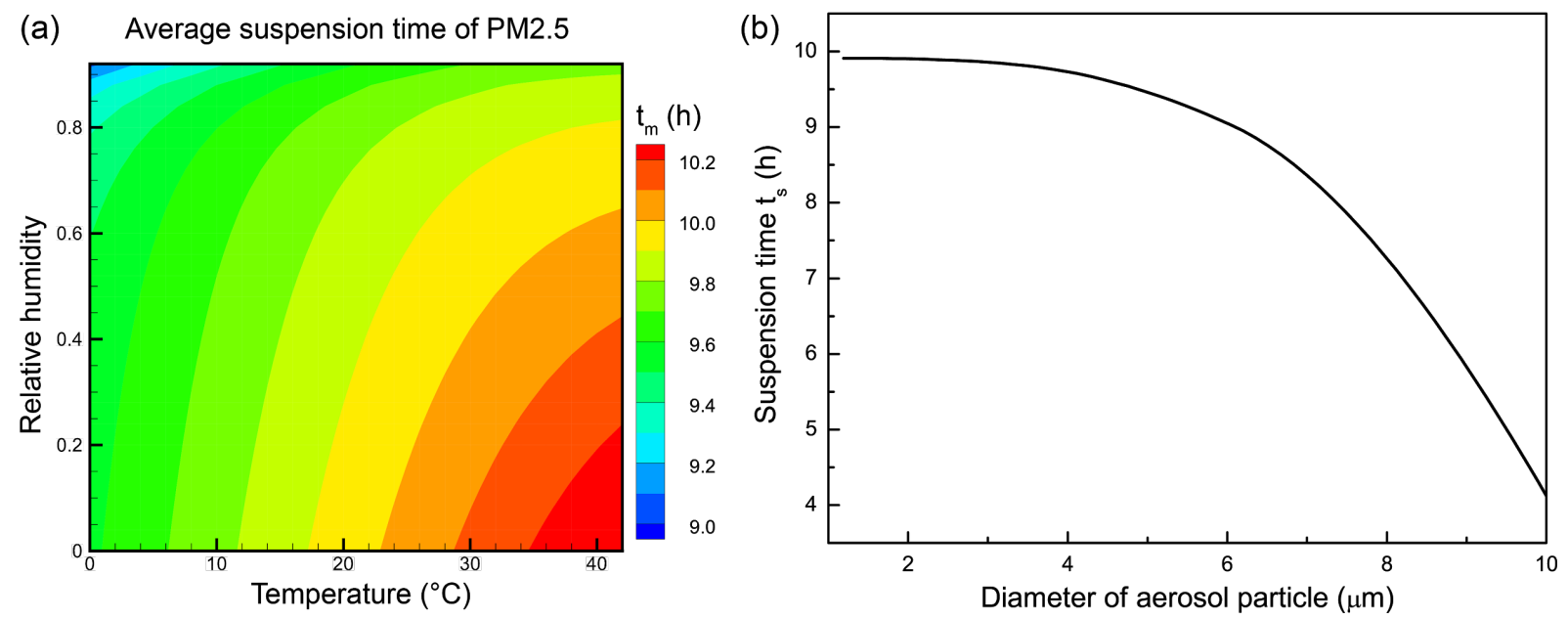

Figure S8. Average suspension time of PM2.5 under different environmental conditions

Assume the percentage of droplets that can turn into PM2.5 in speech droplets is $p\left(d_{0}\right) . d_{r}$ is the diameter of the formed aerosol particle after dehydrating. Then the number of PM2.5 that can be produced by constant speaking is $\sum_{d_{0}} N p\left(d_{0}\right)$, where $\mathrm{N}$ is the number of produced droplets per second. After $t_{s}$, the number of the corresponding aerosol particles reaches equilibrium, as the number of newly produced particles is equal to the number of aerosol particles falling on ground. Then the mass of PM2.5 at steady state can be calculated as the summation of PM2.5 produced in a time period of $t_{s}$. Therefore, $m_{d}$ can be calculated:

$$
m_{d=} \rho_{s} \sum \frac{1}{6} \pi d_{r}^{3} N p\left(d_{0}\right) t_{s}\left(d_{0}\right)
$$

In this study, $\mathrm{N}$ is equal to 50 droplets per minute. ${ }^{9}$ Based on equation S20, the total mass of PM2.5 has been computed under different environmental conditions in Figure 3(d).

\section{REFERENCES}

1. W.F. Wells. On air-borne infection: Study II. Droplets and droplet nuclei. Am. J. Epidemiol. 20: 611-618, 1934. 
2. X. Xie, Y. Li, A. Chwang, P. Ho, W. Seto, How far droplets can move in indoor environmentsrevisiting the Wells evaporation-falling curve. Indoor Air. 17, 211-225 (2007).

3. J. Kukkonen, T. Vesala, M. Kulmala, The interdependence of evaporation and settling for airborne freely falling droplets. J. Aerosol Sci. 20, 749-763 (1989).

4. M. Kulmala, T. Vesala, Condensation in the continuum regime. J. Aerosol Sci. 22, 337-346 (1991).

5. R. Wolfel et al. Virological assessment of hospitalized patients with COVID-2019. Nature 581(7809), 465-469 (2020).

6. Y. M. Bar-On et al. Science Forum: SARS-CoV-2 (COVID-19) by the numbers. Elife 9, e57309 (2020).

7. R. Zwanzig. Nonequilibrium statistical mechanics. Oxford University Press, 2001.

8. J. P. Duguid, The size and the duration of air-carriage of respiratory droplets and dropletnuclei. Epidemiol. Infect. 44, 471-479 (1946).

9. S. Asadi, A. S. Wexler, C. D. Cappa, S. Barreda, N. M. Bouvier, W. D. Ristenpart, Aerosol emission and superemission during human speech increase with voice loudness. Sci. Rep. 9, 1-10 (2019). 